\title{
Early hyperostosis frontalis interna found incidentally by NaF18 PET/ CT bone scan
}

\author{
Aung Zaw Win ${ }^{1}$, Carina Mari Aparici ${ }^{1,2}$ \\ 1. Dept. Radiology, Nuclear Medicine section, San Francisco Veteran Affairs Medical Center, San Francisco, USA. 2. Dept. \\ Radiology, Nuclear Medicine section, UCSF, San Francisco, USA. \\ Correspondence: Aung Zaw Win. Address: Division of Nuclear Medicine, Department of Radiology, San Francisco VA \\ Medical Center, 4150 Clement Street, San Francisco, CA 94121, USA. Telephone: 14-152-214-810. Ext. 3051. Fax: \\ 14-157-502-142. Email: Aung.Win2@va.gov
}

Received: November 15, 2011

DOI : $10.5430 /$ jbgc.v2n1p116

Accepted: December 25, 2011 Published: June 1, 2012

URL: http://dx.doi.org/10.5430/jbgc.v2n1p116

\section{Abstract}

The patient is an 80 year old white male who was referred for NaF18 PET/CT bone scan to evaluate for possible prostate cancer metastasis. We found no evidence of prostate cancer metastasis but there was an incidental finding of early hyperostosis frontalis interna in bilateral inner tables of frontal bone on PET/CT scan. The thickness of the inner table of frontle bones was normal on CT scan images; however, increased osteoplastic activity consistent with early active hyperostosis frontalis interna was seen on NaF18 PET/CT images. The patient had no neuropsychological symptoms. To our knowledge, this is the first reported case of early hyperostosis frontalis interna found incidentally by NaF18 PET/CT.

\section{Key words}

NaF18 bone scan, Hyperostosis frontalis interna, PET/CT

\section{I ntroduction}

Hyperostosis frontalis interna (HFI) is an entity that is characterised by the thickening of the inner table of the frontal bone. It usually occurs bilaterally, although a unilateral case has been reported ${ }^{[1]}$. This benign condition may lead to progressive bone overgrowth and can affect cranial nerves I, II, V, VII and VIII. This disorder can be inherited in the autosomal dominant pattern and the treatment is surgical decompression of the impaired cranial nerves ${ }^{[2]}$. HFI is associated with conditions such as frontal headaches, migraine without aura, dementia, insomnia, apathy, memory disturbance, postural instability, psychoneurosis, epilepsy, obesity, pregnancy, acromegaly, virilism, hypogonadism, hypertrichosis, hyperprolactinemia and diabetes ${ }^{[3,4,5]}$. HFI can compress the brain tissue and even lead to atrophy of the brain. Surgical decompression is recommended in such cases ${ }^{[6]}$.

It is typically associated with elderly postmenopausal women due to disordered bone metabolism as a result of increased androgen and prolactin levels. HFI has become more common in modern times. The incidence of HFI has been reported as $5 \%$ for males in general ${ }^{[7]}$ and $11.8 \%$ for women aged $20-29$ years and $44.2 \%$ for women over 80 years of age. HFI usually stabilizes with time and increasing age ${ }^{[8]}$. 
The severity of HFI can vary from small, isolated nodules to bilateral continuous bony overgrowth that spares the midline. It does not extend beyond the middle meningeal artery even in advanced cases ${ }^{[7]}$. In HFI, the diploic space, between the inner and outer tables, is increased and it contains the hematopoietically active marrow ${ }^{[9]}$. There are no differences in diploic space based on sex, age, weight and height. The disease can spread onto the dura and falx cerebri with abnormal bone deposition.

In the past, HFI was thought to be a part of other syndromes such as Morgagni's syndrome (HFI, obesity,virilism), Stewart-Morel syndrome (HFI, obesity, mental disturbances), Troell-Junet syndrome (HFI, acromegaly, toxic goiter, and diabetes mellitus), but it is now discovered to be a separate phenomenon of its own ${ }^{[8]}$.

The etiology of HFI can be varied and hormonal, lifestyle, environmental and even genetic causes have been reported in the literature. Obese persons and people who use contraceptives and steroids are more prone to have HFI. Phytoestrogens from diet have also been implicated ${ }^{[8]}$. The hormonal theory, which has the most evidence, supports estrogen imbalance as the main factor in the development of HFI. Yet, other hormones such as testosterone, leptin and enzymes such as alkaline phosphatase have also been associated with HFI. High levels of leptin and alkaline phosphatase have been found in separate studies involving patients with HFI ${ }^{[8]}$. In cases of testicular atrophy, Klinefilter syndrome, male hypogonadism, and prostate cancer treated with androgen suppression therapy; there is a decrease in androgen resulting in an increase in

the estrogen to androgen ratio ${ }^{[6]}$. Estrogen preserves bone mass, decrease bone turnover and prolongs the life span of osteoblasts and osteoclasts. In HFI, there is an abnormal increase in osteoblastic activity.

\section{Case presentation}

The patient is an 80 year old obese white male with a history of recurrent prostate cancer status post radiation therapy, basal cell carcinoma on right face, aortic valve stenosis, hypogonadism, BPH, renal failure, hypercholesterolemia, HTN, insomnia, DM II, gout, GERD and osteoarthritis. He was first diagnosed with prostate cancer in 2001 with corresponding PSA level of $11.2 \mathrm{ng} / \mathrm{mL}$ (Normal: 0-4 ng/mL) and Gleason score of 8 (Gleason scores range from 2 to 10 ). The patient was treated with electron beam radiation therapy (EBRT) and Zoladex for 12 months. His PSA level remained $<0.1$ $\mathrm{ng} / \mathrm{mL}$ for 2 years after the treatment. The patient became hypogonadal after the EBRT. However, the PSA began to rise slowly starting from 2003 and in 2009, PSA level was $1.5 \mathrm{ng} / \mathrm{mL}$. He had rising PSA level of $5.11 \mathrm{ng} / \mathrm{mL}$ in November 2010, two months before the bone scan, up from $1.55 \mathrm{ng} / \mathrm{mL}$ about a year ago in 2009. His testosterone level in November 2010 was $49.3 \mathrm{ng} / \mathrm{dL}$ (reference range 175-781 ng/dL). A TRUS biopsy was performed in December 2010, a month before the bone scan, and the pathology report gave a diagnosis of adenocarcinoma with the Gleason score of 9. Combined androgen blockade (CAB) hormone therapy with Casodex/Zoladex was started in the same month as the bone scan. He also underwent salvage radiation therapy with cyberknife and he has been doing well since the procedure.

Urology clinic referred him to us in January 2011 for a bone scan to evaluate for possible prostate cancer metastasis. The patient was complaining of chronic fatigue and bilateral knee pain from osteoarthritis during the visit. He had no other acute problems.

Currently, he has no more complaints of chronic fatigue. His last PSA level 10 months after the bone scan was $<0.05$ $\mathrm{ng} / \mathrm{mL}$. The patient will be continued on CAB and PSA levels will be followed every 3 months.

\section{Discussion}

Our patient has hypogonadism, hypercholesterolemia, DM II, gout and obesity, risk factors all associated with HFI. Yet, HFI in our patient can be an independent primary entity, completely unrelated to his other existing co-morbidities. The disease is predominantly found in post-menopausal females and we present a case of an incidental finding of HFI in an elderly man. Our patient has no neuropsychiatric symptoms but HFI can present with non-specific symptoms such as 
headache and memory loss. There is a case reported in the literature about migraine in a patient with HFI and giant cell arteritis ${ }^{[10]}$. Thus, other etiologies have to be ruled out first and radiologic imaging is needed to diagnose HFI.

May et al. reported that in advanced HFI, bony nodules are shaped as elongated parallel ridges that are perpendicular to the mid-sagittal line on CT images ${ }^{[7]}$. Hershkovitz et al. developed their own 3D reconstruction and volume rendering method to classify four types of HFI: single or multiple isolated nodules with less than 10mm thickening (type A), nodular bone overgrowth that occupies less than $25 \%$ of inner surface area (type B), irregular thickening of up to $50 \%$ of inner surface area (type C) and continuous overgrowth of more than $50 \%$ of inner surface area (type D) ${ }^{[7]}$. Our case is not even type A according to Hershkovitz et al because the disease is in its very early stages and it is not detectable by CT imaging (see Figure 4). On the PET/CT fusion images of our patient, we can appreciate the presence of HFI but it is due to the osteoblastic activity in the frontal bones and not due to the abnormal bone growth.

HFI is appreciated in the whole body bone scan (see Figure 1), but more clearly on transaxial PET/CT fusion image at the level of the frontal bones (see Figure 2 and 3). Hence, this incidental finding basically indicates an early diagnosis of HFI, before the anatomical evidence of bone thickening is able to be identified.

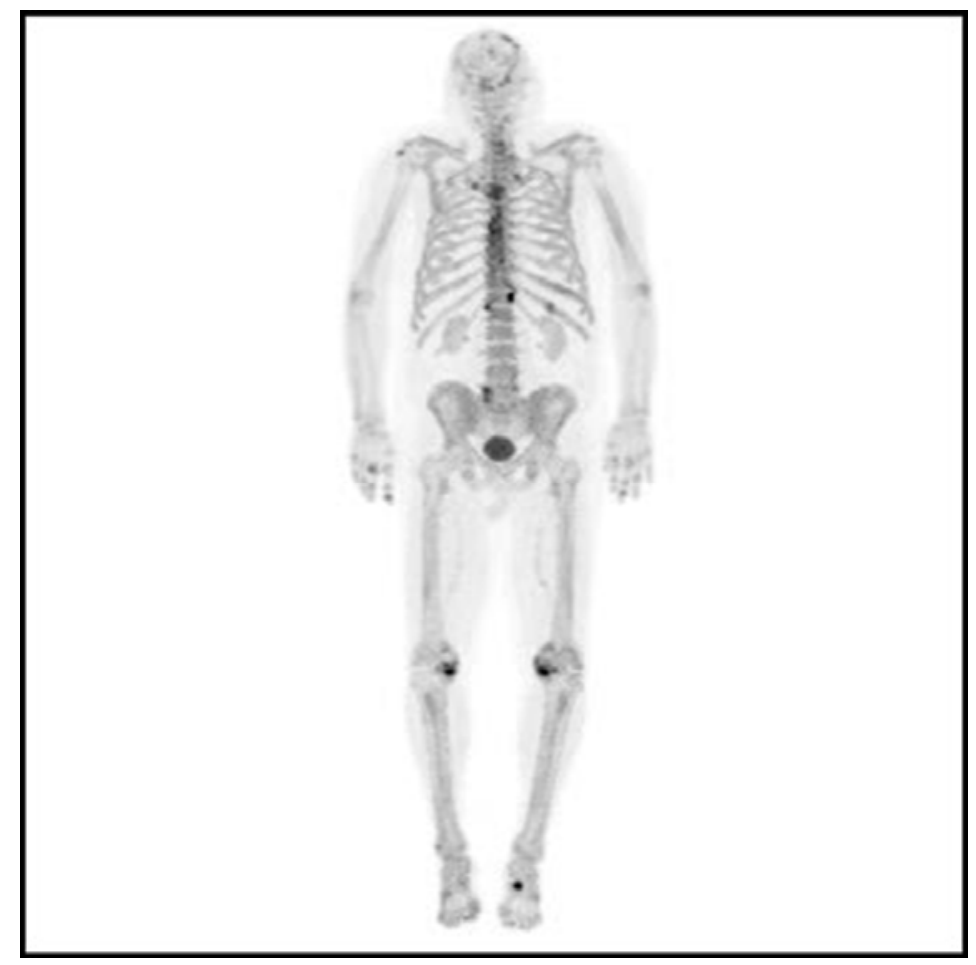

Figure 1. 60 minutes following the uneventful intravenous administration of $12 \mathrm{mCi}$ of NaF18, CT transmission image without intravenous contrast was acquired from the vertex to the toes for attenuation correction and anatomic localization. This was followed by a PET emission scan over the same anatomical regions. A rotating 3D MIP, as well as axial, coronal and sagittal PET images with and without attenuation correction was interpreted. Acquired CT and fused PET/CT images were reviewed alongside the PET images. Whole body MIP images show abnormal osteoblastic activity in the skull, without evidence of metastatic bone disease in the rest of the skeleton. Osteoblastic end-plate degenerative joint disease, osteophytosis and facet joint disease are identified along the spine. Osteoblastic degenerative joint disease is apparent in the medial compartment of both knees and left mid foot. Also, there are persistent signs of remodeling in old bilateral rib trauma. 


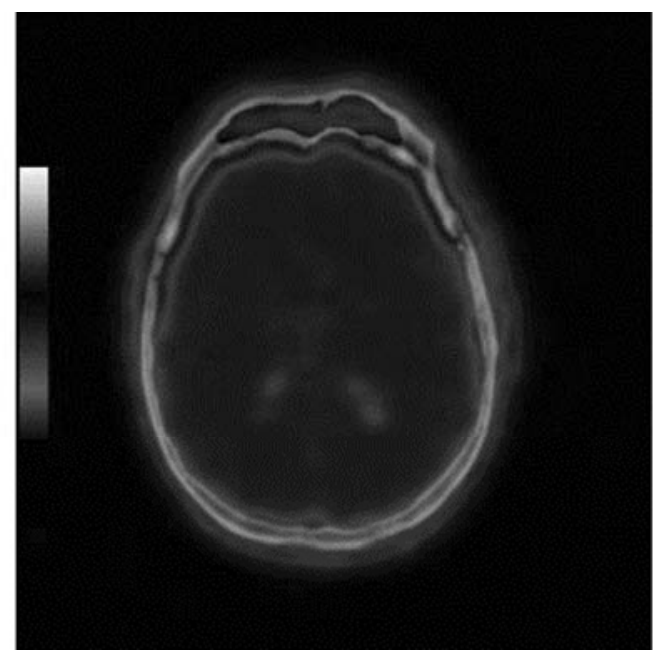

Figure 2 and 3. Acquired CT and fused PET/CT images were reviewed alongside the PET images. Cross sectional transaxial NaF18 and corresponding fusion PET/CT image at the level of the frontal bones shows increased patchy osteoblastic activity just in the inner table of both frontal bones. The left side shows slightly increased activity than the right.

Figure 4. CT transmission scan image of the cranium at the same level shows no evidence of bone thickening. Increased patchy osteoblastic activity just along the inner table of the frontal bones is very consistent with the definition of hyperostosis frontalis interna in spite of no abnormal bone thickening on the CT image.

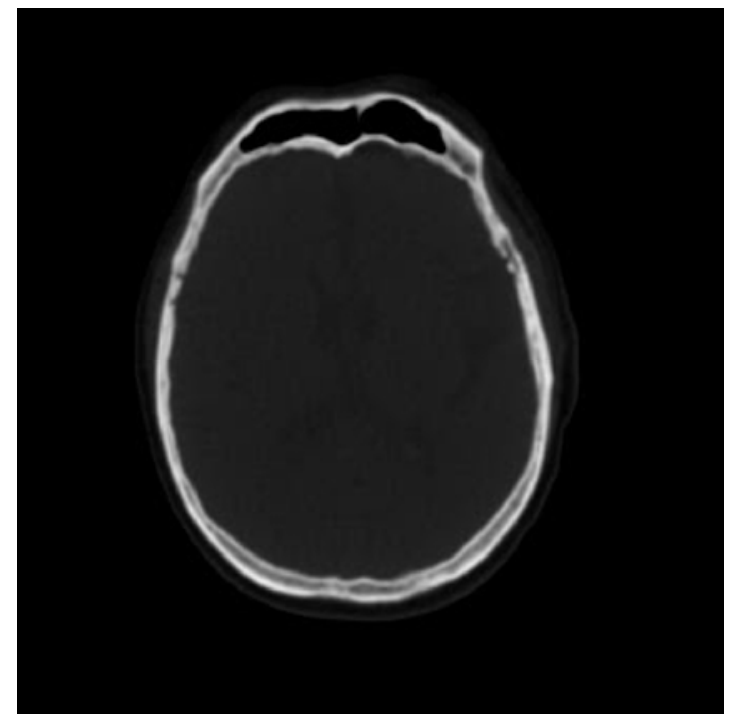

\section{References}

[1] Hasegawa T, Ito H, Yamamoto S. Unilateral Hyperostosis Frontalis Interna - Case-Report. Journal of Neurosurgery. 1983; 59: 710-13. PMid: 6886795. http://dx.doi.org/10.3171/jns.1983.59.4.0710

[2] Waterval JJ, Stokroos RJ, Bauer NJC, et al. Phenotypic manifestations and management of hyperostosis cranialis interna, a hereditary bone dysplasia affecting the calvaria and the skull base. Am J Med Genet Part A. 2010; 152A: 547-55. PMid: 20140965. http://dx.doi.org/10.1002/ajmg.a.33205

[3] Kocabas H, Sezer I, Melikoglu A, et al. Hyperostosis frontalis interna in a patient with giant cell arteritis. Mod Rheumatology. 2008; 18: 181-83. PMid: 18250961. http://dx.doi.org/10.1007/s10165-008-0021-8

[4] Fulton J, Shand J, Ritchie D, et al. Hyperostosis frontalis interna, acromegaly and Hyperprolactinaemia. Postgrad Med J. 1990; 66: 16-19. PMid: 2349162. http://dx.doi.org/10.1136/pgmj.66.771.16 
[5] Yamakawa K, Mizutani K, Takahashi M, et al. Hyperostosis frontalis interna associated with hypogonadism in an elderly man. Age and Ageing. 2006; 35: 202-03. PMid: 16431852. http://dx.doi.org/10.1093/ageing/afj051

[6] Ramchandren S, Liebeskind D.S. Headache in a patient with Klinefelter's syndrome and hyperostosis frontalis interna. J Headache Pain. 2007; 8: 342-44. PMid: 18071629. http://dx.doi.org/10.1007/s10194-007-0426-3

[7] May H, Peled N, Dar G, Abbas J, Hershkovitz I. Hyperostosis Frontalis Interna: What Does it Tell Us About our Health? American Journal of Human Biology. 2011; 23: 392-97. PMid: 21387460. http://dx.doi.org/10.1002/ajhb.21156

[8] Talarica Jr. E.F, Prather A.D, Hardt K.D. A Case of Extensive Hyperostosis Frontalis Interna in an 87-Year-Old Female Human Cadaver. Clinical Anatomy. 2008; 21: 259-68. PMid: 18351650. http://dx.doi.org/10.1002/ca.20613

[9] Torres M.A, Palestro C.J. Leukocyte-Marrow Scintigraphy in Hyperostosis Frontalis Interna. J Nucl Med. 1997; 38: 1283-85. PMid: 9255168.

[10] Kocabas H, Sezer I, Melikoglu M.A, Gurbuz U, Illeez O, Ozbudak I.H, Butun B. Hyperostosis frontalis interna in a patient with giant cell arteritis. Mod Rheumatol. 2008; 18: 181-83. PMid: 18250961. http://dx.doi.org/10.1007/s10165-008-0021-8 